\title{
Emergency coronary artery bypass surgery after intracoronary thrombolysis for evolving myocardial infarction
}

\author{
PHILIP KAY, AFTAB AHMAD, STORM FLOTEN, ALBERT STARR \\ From St Vincent Medical Center, Portland, Oregon, USA
}

SUMMARY Sixteen patients underwent emergency coronary artery bypass surgery immediately after intracoronary streptokinase infusion for acute evolving myocardial infarction. Of these, 11 patients had $70 \%$ residual stenosis in the recanalised vessel, and in five thrombolysis was unsuccessful. There were no hospital deaths. All the patients sustained myocardial necrosis, the peak activity of creatine phosphokinase correlating with the time to reperfusion. Chest tube drainage (mean $960 \mathrm{ml}$ ) was significantly higher than for control patients but did not correlate with the total dosage of streptokinase. No patients had further myocardial infarction or developed recurrent angina.

Selected patients may benefit from coronary bypass surgery after intracoronary streptokinase infusion. If necessary this may be performed immediately with low mortality and morbidity.

The importance of left ventricular function in determining the prognosis of patients with coronary artery disease ${ }^{12}$ has directed attempts towards early restoration of coronary blood flow in patients with acute evolving myocardial infarction. The infusion of streptokinase into the appropriate coronary ostium restored patency in $72-95 \%$ of patients. ${ }^{34}$

Nevertheless, though successful streptokinase treatment results in thrombolysis it does not remove the underlying coronary artery stenosis, and thus secondary occlusion with reinfarction remains a problem. ${ }^{56}$ Serruys et al suggested a combination of transluminal angioplasty after successful thrombolysis, ${ }^{3}$ while Phillips et al recommended coronary bypass surgery for stenoses not responding to streptokinase treatment. ${ }^{7}$

To obviate both these problems we adopted a policy of immediate coronary bypass surgery after intracoronary streptokinase infusion in selected patients.

\section{Patients and methods}

During 1983, 28 patients admitted to this hospital with acute evolving myocardial infarction ${ }^{8}$ were treated by intracoronary streptokinase infusion. Throm-

Requests for reprints to Dr Albert Starr, St Vincent Medical Center, 9155 SW Barnes Road, Portland, Oregon 97225, USA.

Accepted for publication 14 November 1984 bolysis was unsuccessful in five (18\%) patients, including two with cardiogenic shock and one with intractable ventricular arrhythmias. Eleven (39\%) patients had residual stenosis of $>70 \%$ in the recanalised vessel and were considered at high risk of reocclusion. These 16 patients underwent immediate coronary bypass surgery, and they constitute the study group.

All 16 patients were male, with a mean age of 53 (range 38-60) years. All presented with unremitting angina associated with ST segment elevation on the electrocardiogram. None had developed $Q$ waves. This was the first coronary occlusion in all patients. The mean interval between the onset of pain and coronary arteriography was $2 \cdot 2$ (range $1-4$ ) hours. All patients had occlusion of one major coronary artery (anterior descending (12), right coronary artery (3), large first obtuse marginal (1)). In each case the left ventriculogram showed segmental wall motion abnormalities associated with the occluded vessel. An initial bolus of 20000 units of streptokinase was infused into the occluded coronary artery followed by an infusion of 5000 units/min. The mean dose of streptokinase was 200000 units (range 95000 340000 units). In two patients with cardiogenic shock streptokinase infusion was stopped after 15 minutes (equivalent to 95000 units). A third patient developed intractable ventricular arrhythmias, and the streptokinase infusion was stopped after 100000 


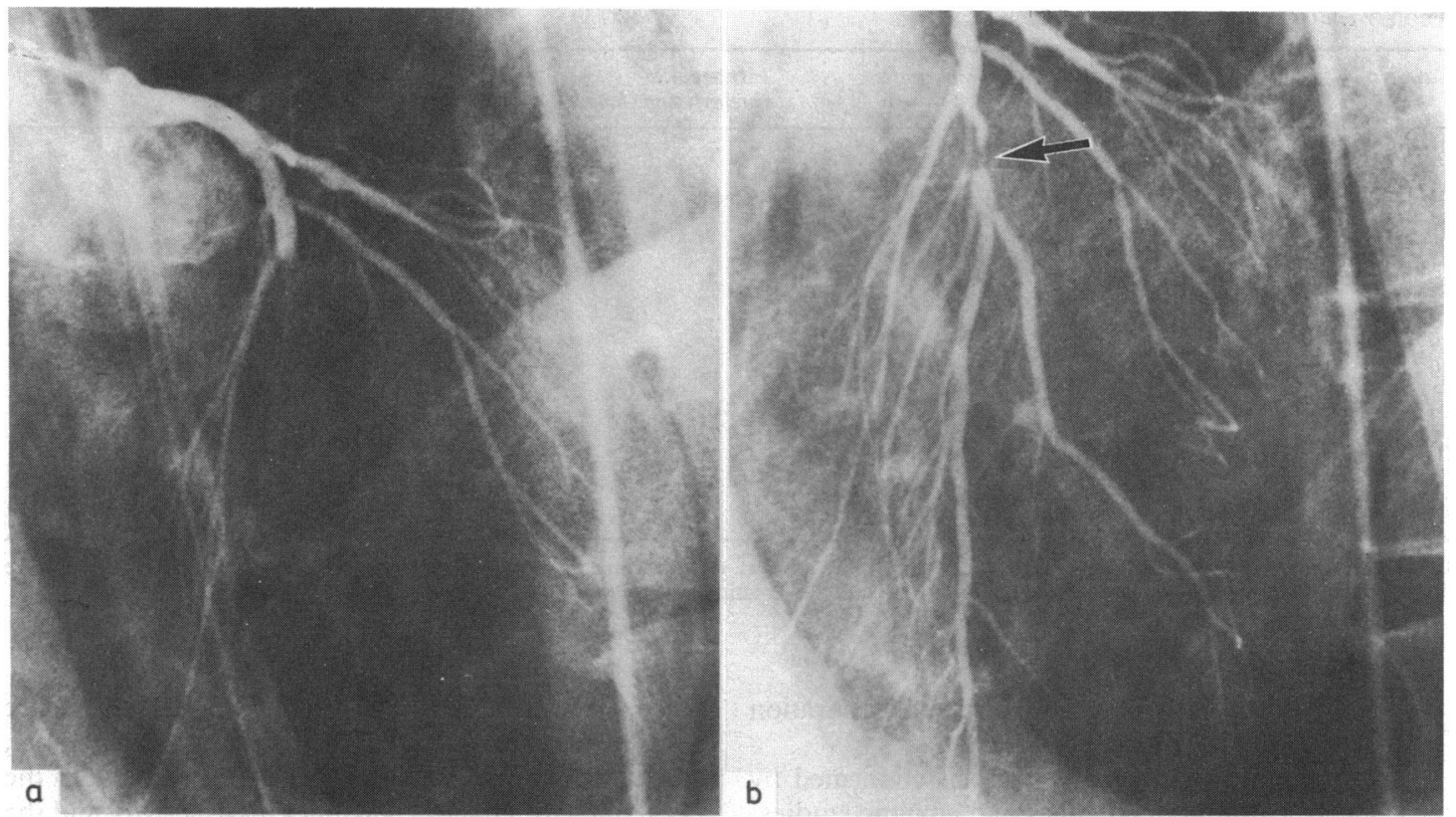

Fig. 1 Coronary ateriograms (a) before and (b) after successful intracoronary thrombolysis of occluded anterior descending artery. (b) shows residual $90 \%$ stenosis (arrow).

units had been given. All recanalised vessels had proximal stenoses of $>70 \%$, and in eight patients the stenosis was $>90 \%$ (Fig. 1).

The patients were transferred immediately from the catheter laboratory to the operating room. Cardiopulmonary bypass was rapidly instituted between the right atrium and the ascending aorta. Coronary artery bypass surgery was performed using the technique of intermittent ischaemic arrest at moderate hypothermia $\left(30^{\circ} \mathrm{C}\right)$. The occluded artery was grafted first so that the time between the onset of pain and complete reperfusion of the occluded artery was less than six hours in each case. All other major vessels with stenoses of $>50 \%$ were then serially bypassed. Eight patients received three grafts, five patients two grafts, and three patients one graft. At the end of the operation the patients were given 10 units of cryoprecipitate, 10 units of platelets, and 2 units of fresh frozen plasma.

In the immediate postoperative period the development of myocardial necrosis was monitored by serial creatine phosphokinase measurements and electrocardiographic changes. Serum creatine phosphokinase activity was measured at eight, 16 , and 24 hours after admission to hospital. Electrocardiograms were recorded on the first, second, third, and seventh postoperative day.

\section{Results}

There were no hospital deaths. Four patients required positive inotropic support (dobutamine $5-12 \mu \mathrm{g}$ / $\mathrm{kg} / \mathrm{min}$ ) and one balloon counterpulsation. Six patients received a lignocaine infusion $(2 \mathrm{mg} / \mathrm{min})$ for ventricular arrhythmias. The mean blood loss through the chest tube drain was 960 (SD 385) $\mathrm{ml}$. This was higher than for control patients but did not correlate with the total dose of streptokinase given

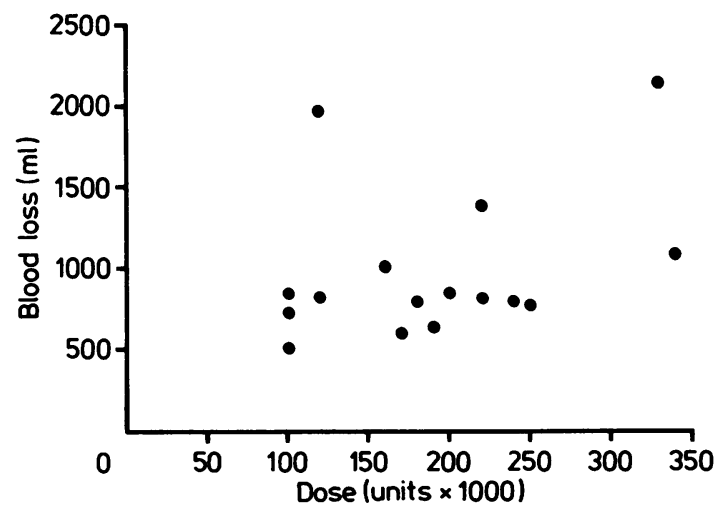

Fig. 2 Relation between blood loss and streptokinase dose. 
Table Indices of myocardial necrosis

\begin{tabular}{|c|c|c|c|c|c|}
\hline Case No & Occluded vessel & No of grafts & $\begin{array}{l}\text { Interval to } \\
\text { reperfusion (hours) }\end{array}$ & New ECG changes & $\begin{array}{l}\text { Peak CPK activity } \\
\text { (IU/l) }\end{array}$ \\
\hline $\begin{array}{r}1 \\
2 \\
3 \\
4 \\
5 \\
6 \\
7 \\
8 \\
9 \\
10 \\
11 \\
12 \\
13 \\
14 \\
15 \\
16\end{array}$ & $\begin{array}{l}\text { LAD } \\
\text { LAD } \\
\text { LAD } \\
\text { LAD } \\
\text { RCA } \\
\text { LAD } \\
\text { LAD } \\
\text { LAD } \\
\text { Lat Cx } \\
\text { LAD } \\
\text { RCA } \\
\text { LAD } \\
\text { LAD } \\
\text { LAD } \\
\text { LAD } \\
\text { RCA }\end{array}$ & $\begin{array}{l}1 \\
1 \\
2 \\
3 \\
1 \\
2 \\
3 \\
2 \\
2 \\
3 \\
2 \\
3 \\
3 \\
3 \\
3 \\
3\end{array}$ & $\begin{array}{l}2 \\
2 \\
2 \\
2 \\
3 \\
3 \\
3 \\
3 \\
3 \\
3 \\
4 \\
4 \\
4 \\
5 \\
6 \\
6\end{array}$ & $\begin{array}{l}\text { Normal } \\
\text { Normal } \\
\mathbf{R} \\
\mathbf{R} \\
\mathbf{Q} \\
\mathbf{R} \\
\mathbf{R} \\
\mathbf{R} \\
\mathbf{Q} \\
\mathbf{Q} \\
\mathbf{Q} \\
\mathbf{R} \\
\mathbf{Q} \\
\mathbf{R} \\
\mathbf{R} \\
\mathbf{Q}\end{array}$ & $\begin{array}{l}540 \\
890 \\
990 \\
2500 \\
1800 \\
1900 \\
1950 \\
2100 \\
2500 \\
3500 \\
2800 \\
3000 \\
3700 \\
2000 \\
2500 \\
5500\end{array}$ \\
\hline
\end{tabular}

LAD, left anterior descending; Lat $\mathrm{Cx}$, lateral circumflex; RCA, right coronary artery; ECG, electrocardiogram; $R$, loss of $R$ wave progression across anterior chest leads; $Q$, new $Q$ waves; CPK, creatine phosphokinase.

$(\mathrm{r}=0.36)$ (Fig. 2). One patient required re-exploration for excessive haemorrhage.

All patients had myocardial necrosis confirmed by serial electrocardiogram changes and enzyme studies. The Table summarises the data of individual patients. All four patients with occlusions of the right coronary artery or obtuse marginal vessels and two with occlusions of the anterior descending artery developed new $Q$ waves. Eight patients with occlusions of the anterior descending artery showed a loss of $R$ wave progression on serial electrocardiograms. In two patients (Table, cases 1 and 2) the electrocardiogram returned to normal. The postoperative value for creatine phosphokinase activity was abnormally raised (mean 2323 (SD 1561) units) with a positive MB isoenzyme in all patients. Three patients with occlusion of the anterior descending artery underwent successful thrombolysis within two hours of the onset of

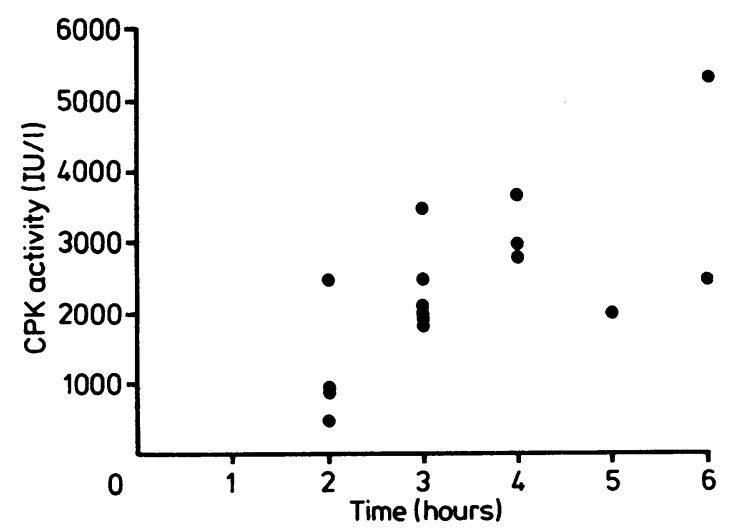

Fig. 3 Relation between peak value of creatine phosphokinase $(C P K)$ activity and time to reperfusion. pain. The highest value for creatine phosphokinase activity in these patients was $<1000$ units (Table, cases 1-3). Figure 3 shows the correlation between the peak value for creatine phosphokinase activity and the time interval to reperfusion $(r=0.67, p<0.01)$.

Follow up in this series was short (mean 8 months). Nevertheless, to date no patients have experienced further angina or suffered myocardial infarction.

\section{Discussion}

An analysis of the results of the 63 coronary care units in Boston, Massachusetts, showed no perceptible fall in the hospital mortality from acute myocardial infarction between 1973-74 and 1978-79.9 The most rational approach to the management of acute evolving myocardial infarction is the restoration of anterograde blood flow. After coronary artery occlusion in dogs, necrosis begins in the subendocardial region and spreads outwards to the subepicardial layer. This wavefront of necrosis can be arrested by reperfusion, ${ }^{10}$ the final size of the infarction being a function of the duration of ischaemia and the ischaemic tolerance of a given patient. This in turn depends on the number and size of collateral vessels compensating for the occluded artery.

In 1960 Boucek and Murphy infused fibrinolysins into the aortic sinuses of patients with acute myocardial infarction, reporting circumstantial evidence that the manoeuvre resulted in the re-establishment of blood flow. " This technique was refined by Rentrop et al who reported the first successful cases of intracoronary thrombolysis in 1979.12 The sooner the treatment is started, the greater its chance of success. ${ }^{13} 14$ Successful streptokinase treatment has been associated with improved thallium-201 uptake ${ }^{15-17}$ 
and improved wall motion ${ }^{18-20}$ in the ischaemic areas. The clinical results of thrombolysis have also been encouraging. ${ }^{618}$ In the German multicentre study mortality was 7\% among patients in whom reperfusion occurred and $24 \%$ among those in whom the occlusion persisted. ${ }^{6}$ After successful thrombolysis reocclusion has been reported in $17 \%^{3}$ to $25 \%^{5}$ of patients. Serruys et al suggested concomitant balloon dilatation of the residual stenosis after successful thrombolysis, reporting no late reocclusions in 18 patients undergoing this procedure. ${ }^{3}$ Krebber et al have used thallium-201 scintigraphy as a predictor of the salvageability of myocardium immediately after intracoronary thrombolysis to assess patients suitable for early coronary revascularisation. ${ }^{21}$ No details of the patients undergoing this procedure are given, however, nor is the time interval between medical recanalisation and surgical reperfusion stated.

Berg et al have been strong advocates of immediate coronary bypass surgery for acute evolving myocardial infarction. ${ }^{8}$ DeWood et al reported appreciable improvement in global function and regional wall motion in selected patients if surgical reperfusion was performed within six hours of the onset of symptoms of anterior infarction. ${ }^{22}$ Phillips et al used immediate coronary bypass surgery for 21 patients in whom streptokinase treatment failed. ${ }^{7}$ The mean interval to reperfusion was 10 hours in this group, four of which required re-exploration for haemorrhage. Becher et al, however, found no increase in bleeding complications in patients operated on within 24 hours of thrombolysis compared with those undergoing surgery after this period. ${ }^{23}$

The results of our study support the aggressive approach in treating patients with acute evolving myocardial infarction. 7822 Thrombolytic treatment had failed in five patients, two of whom were in cardiogenic shock, while in eight the residual stenosis after successful thrombolysis was $>90 \%$. The anatomy of the latter group of patients was more severe than that reported by Serruys et al, who found that only $19 \%$ of 64 patients undergoing thrombolysis had a residual stenosis of $>70 \% .^{3}$ In no case did the combination of rapid intracoronary thrombolysis followed by immediate coronary bypass surgery prevent myocardial damage. We consider, however, that it may have limited its extent. This was particularly apparent in two patients in whom blood flow was reestablished within two hours of the onset of pain (Table, cases 1 and 2). In these patients peak creatine phosphokinase activity was $<1000 \mathrm{IU} / \mathrm{h}$ and the electrocardiogram returned to normal. The follow up period was short, but to date there have been no deaths, mechanical complications of infarction, or further ischaemic episodes.

Theoretically, all patients having acute evolving myocardial infarction should be revascularised at the earliest possible opportunity. As a prelude all patients will undergo coronary arteriography to delineate the anatomy. Successful thrombolysis with intracoronary streptokinase then provides additional time before a decision regarding surgery must be taken. The length of time depends partly on the residual coronary lesions. Some may be so minor that the infarction can be allowed to run its course and elective surgery planned at a later date when further symptoms occur. ${ }^{24}$ This more elective approach would allow the use of the internal mammary artery which must now be considered as the conduit of choice for the anterior descending artery. ${ }^{25} 26$ In other situations a more aggressive approach may be required. This may take the form of immediate balloon angioplasty ${ }^{3}$ or early surgery.

Since this was not a prospective randomised trial with follow up haemodynamic data, we are unable to conclude that this is the preferred method of treatment. The study simply shows that immediate coronary bypass surgery can be performed effectively after intracoronary thrombolysis. Though postoperative chest tube drainage was significantly higher in this group of patients than after elective coronary bypass surgery, haemorrhage was not an insuperable problem. Indeed in the dosage given (95 000-340 000 units) there was no correlation between the dosage and total blood loss. Though Jutzy et al have shown no difference in the systemic fibrinolytic state assessed by serial determinations of fibrinogen and euglobulin lysis time, ${ }^{27}$ it is likely that the larger doses $>500000$ units) given intravenously ${ }^{28} 29$ may preclude immediate surgery.

\section{References}

1 Bruschke AVG, Proudfit WL, Sones FM Jr. Progress study of 590 consecutive non-surgical cases of coronary disease followed 5-9 years. II Ventriculographic and other correlations. Circulation 1973; 47: 1154-63.

2 Hammermeister KE, Derouen TA, Dodge HT. Variables predictive of survival in patients with coronary disease. Selection by univariate and multivariate analyses from the clinical, electrocardiographic, exercise, arteriographic and quantitative angiographic evaluations. Circulation 1979; 59: 421-35.

3 Serruys PW, Wijns W, Van den Brand M, et al. Is transluminal angioplasty mandatory after successful thrombolysis? Quantitative coronary angiographic study. $\mathrm{Br}$ Heart f 1983; 50: 257-65.

4 Ganz W, Buchbinder N, Marcus H, et al. Intracoronary thrombolysis in evolving myocardial infarction. Am Heart f 1981; 101: 4-13.

5 Merx W, Dörr R, Rentrop P, et al. Evaluation of the effectiveness of intracoronary streptokinase infusion in acute myocardial infarction: postprocedure management and hospital course in 204 patients. Am Heart $\mathcal{F}$ 1981; 
102: $1181-7$.

6 Mathey DG, Kuck KH, Tilsner V, Krebber HJ, Bleifield W. Nonsurgical coronary artery recanalization in acute transmural myocardial infarction. Circulation 1981; 63: 489-97.

7 Phillips SJ, Kongtahworn C, Skinner JR, Zeff RH. Emergency coronary artery reperfusion: a choice therapy for evolving myocardial infarction. Results in 339 patients. F Thorac Cardiovasc Surg 1983; 86: 679-88.

8 Berg R Jr, Selinger SL, Leonard JJ, Grunwald RP, O'Grady WP. Immediate coronary artery by-pass for acute evolving myocardial infarction. $\mathcal{F}$ Thorac Cardiovasc Surg 1981; 81: 493-7.

9 Goldman L, Cook F, Hashimoto B, Stone P, Muller J, Loscalzo A. Evidence that hospital care for acute myocardial infarction has not contributed to the decline in coronary mortality between 1973-4 and 1978-9. Circulation 1982; 65: 936-42.

10 Reimer KA, Lowe JE, Rasmussen MM, Jennings RB. The wavefront phenomenon of ischemic cell death. I Myocardial infarction size vs. duration of coronary occlusion in dogs. Circulation 1977; 56: 786-94.

11 Boucek RJ, Murphy WP Jr. Segmental perfusion of the coronary arteries with fibrinolysin in man following a myocardial infarction. Am f Cardiol 1960; 6: 525-33.

12 Rentrop P, Blanke H, Kousche KR, et al. Acute myocardial infarction: intracoronary application of nitroglycerin and streptokinase. Clin Cardiol 1979; 2: 354 63.

13 Rutsch W, Schartl M, Mathey D, et al. Percutaneous transluminal coronary recanalization: procedure, results, and acute complications. Am Heart $\mathcal{F}$ 1981; 102: 117881.

14 Serruys PW, van den Brand M, Hooghoudt TEH, et al. Coronary recanalization in acute myocardial infarction: immediate results and potential risks. Eur Heart $\mathcal{F} 1982$; 3: 404-15.

15 Reduto LA, Freund GC, Gaeta JM, et al. Coronary artery reperfusion in acute myocardial infarction: beneficial effects of intracoronary streptokinase on left ventricular salvage and performance. Am Heart $\mathcal{f}$ 1981; 102: 1168-77.

16 Schwartz F, Schuler G, Katus H, et al. Intracoronary thrombolysis in acute myocardial infarction: correlations among serum enzyme, scintigraphic and hemodynamic findings. Am $\mathcal{F}$ Cardiol 1982; 50: 32-8.

17 Markis JE, Malagold M, Parker JA, et al. Myocardial salvage after intracoronary thrombolysis with streptokinase in acute myocardial infarction. Assessment by intracoronary thallium-201. $N$ Engl $f$ Med 1981; 305: $777-82$.
18 Cribier A, Berland J, Champoud O, Moore N, Behar P, Letac B. Intracoronary thrombolysis in evolving myocardial infarction. Sequential angiographic analysis of left ventricular performance. Br Heart $\mathcal{F} 1983$; 50: 401-10.

19 Anderson JL, Marshall HW, Bray BE, et al. A randomized trial of intracoronary streptokinase in the treatment of acute myocardial infarction. N Engl F Med 1983; 308:1312-8.

20 Sheehan FH, Mathey DG, Schofer J, Krebber HJ, Dodge HT. Effect of interventions in salvaging left ventricular function in acute myocardial infarction: a study of intracoronary streptokinase. Am $\mathcal{F}$ Cardiol 1983; 52: 431-8.

21 Krebber HJ, Schofer J, Mathey D, Montz R, Kalmar P, Rodewald G. Intracoronary thallium 201 scintigraphy as an immediate predictor of salvaged myocardium following intracoronary lysis. $\mathcal{F}$ Thorac Cardiovasc Surg 1984; 87: 27-34.

22 Dewood MA, Heit J, Spores J, et al. Anterior transmural myocardial infarction: effects of surgical coronary reperfusion on global and regional left ventricular function. $\mathcal{F}$ Am Coll Cardiol 1983; 1: 1223-34.

23 Becher H, Schröder C, Mathey D, Krebber HJ, Tilsner $\mathrm{V}$, Bleifeld $\mathrm{W}$. Coronary artery by-pass grafting within 24 hours after intracoronary thrombolysis-risk of bleeding [Abstract]. Circulation 1983; 68 (suppl III): 115.

24 CASS Principal Investigators and their Associates. Coronary artery surgery study (CASS): a randomized trial of coronary artery by-pass surgery. Survival data. Circulation 1983; 68: 939-50.

25 Singh RN, Sosa JA, Green GE. Internal mammary artery versus saphenous vein graft. Comparative performance in patients with combined revascularisation. $\mathrm{Br} \mathrm{Heart} \mathcal{f}$ 1983; 50: 48-58.

26 Jones JW, Ochsner JL, Mills NL, Hughes L. The internal mammary by-pass graft. A superior second coronary artery. F Thorac Cardiovasc Surg 1978; 75: 625-31.

27 Jutzy KR, Berte LE, Alderman EL, et al. Relation of systemic fibrinolytic state with route of streptokinase administration and recanalization [Abstract]. Circulation 1983; 68 (suppl III): 39.

28 Saltups A, Boxall J, Ho B. Intracoronary versus intravenous streptokinase in acute myocardial infarction [Abstract]. Circulation 1983; 68 (suppl III): 119.

29 Olson HG, Lyons KP, Butman S, Piters KM, Gardin JM. A randomized controlled trial of intravenous streptokinase in acute transmural myocardial infarction. Preliminary observations [Abstract]. Circulation 1983; 68 (suppl III): 121. 